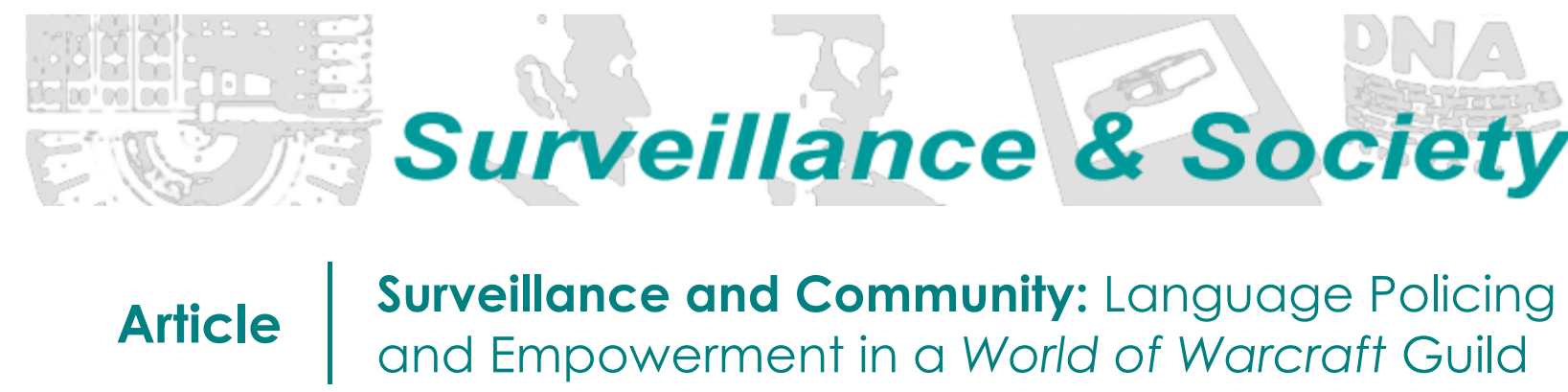

\title{
Lauren B. Collister
}

University of Pittsburgh, US.

lbc8@pitt.edu

\begin{abstract}
This case study of a World of Warcraft guild explores the relationship between participatory surveillance, public discipline, empowerment, and fun. The guild under investigation in this paper is a self-labeled "safe space" guild for female, LGBT, and other minority members of the gaming population. To promote the safe space environment, the guild's members actively enforce prohibitions against offensive language. A comparison is made between the participatory surveillance model employed by the members of the guild and the top-down policies and discipline enacted by the parent company, Blizzard Entertainment; this comparison demonstrates the effects of co-existing models of surveillance in the game community. Furthermore, the effects of the guild's practice of public discipline of rule breakers are analyzed as a soft form of shaming that enhances the effects of the guild's rules. Finally, by examining reactions from members of the guild, personal and community empowerment are the outcomes of participation in the system. Recommendations are made to incorporate elements of participatory surveillance into games in conjunction with unilateral surveillance typically employed by game developers.
\end{abstract}

\section{Introduction}

Surveillance has increasingly become part of the landscape of research in online gaming and online communities. Albrechtslund and Dubbeld (2005) suggest that thinking about surveillance "from the perspective of the fun it could bring" can contribute to developing analyses of surveillance in unexpected places such as online gaming communities (2005: 220). Games such as The Sims center on surveillance tactics, featuring an all-seeing and all-knowing player as the core of the game (Martin 2012); furthermore, in multiplayer online games such as World of Warcraft or League of Legends, players know that they are being watched by the game masters for potential disruptions or violations of rules. Especially in games that involve interaction with other players, surveillance of player behavior has become an expected part of the game experience as well as a critical component of the possibilities of fun.

To reconcile the idea of fun with traditional views of surveillance which characterize the experience of the surveilled subject to one of oppression or coercion (Ball 2009), one must explore how viewpoints of surveillance have changed from the perspective of the surveilled subject. Kirstie Ball says in her analysis of the subjects of surveillance, "surveillance may be tolerated or even sought after because the giving of data satisfies individual anxieties, or may represent patriotic or participative values to the individual" (2009: 641). Complementary to this shift to tolerance of surveillance is the concept of participatory surveillance, defined using a combination of insights into alternate models of surveillance as a mutual monitoring situation in which participants knowingly watch each other in the pursuit of some goal or state. Participatory surveillance is related to reciprocal surveillance (Regan and Steeves 2010) and lateral 
surveillance (Andrejevic 2005) and is distinct from the one-way top-down model of surveillance. In participatory surveillance, an individual watches known others and, in turn, those known others are watching the individual; being part of a participatory surveillance situation can give a feeling of increased agency for the surveilled subjects.

In his 2008 work on surveillance in social networking, Anders Albrechtslund discusses participatory surveillance as encompassing user empowerment, the building of subjectivity, sharing practices rather than information trade, and mutuality. In observing practices on social networks, Albrechtslund suggests that surveillance practices online are not about destroying subjectivity, as is the case in hierarchical conceptions of surveillance; rather, in social networking, surveillance is about building subjectivity of both the watcher and the surveilled subjects. Furthermore, Albrechtslund argues, surveillance practices in online social networking can result in the empowerment of its users by facilitating new ways of constructing identity, meeting friends, and socializing. The users are no longer passive in the surveillance process - they are agents who are free to take action and communicate. Albrechtslund concludes, "online social networking therefore illustrates that surveillance-as a mutual, empowering and subjectivity building practice — is fundamentally social.”

Surveillance in this new model can be empowering to the individuals in the system. In the words of Regan and Steeves (2010: 155): "users participate in a type of multi-directional surveillance in which the many watch the one watching the many, and in which the self watches the self. In this context, empowerment may occur in the interstitial spaces between the top-down constraints which have been engineered into the site itself, as young people interact with each other and with their online environment." Albrechtslund describes the outcome of this multi-directional surveillance as empowerment on personal, group, and community levels; the individual may develop their skills as a result of self-observation, and may develop a growing sense of self-belonging as they observe the actions of their community members. In the long run, empowerment may even reach a citizenship level, in which individuals feel as though they are contributing to a cause or a change in social policy by watching and being watched.

In this work, I will describe a case of an online gaming community in which participatory surveillance, situated inside of a larger uni-directional surveillance culture, empowered a set of players to change their own habits as well as contribute to social change. The community being described is a guild in World of Warcraft $(W o W)$, which operated under a set of rules designed to foster an accepting environment for people who felt marginalized by the discourse of the broader $W o W$ gaming community. The primary way that the guild accomplished this was through regulations on the use of offensive and non-inclusive language and public surveillance and punishment for those who disobeyed the rules. I describe how this participatory surveillance scenario in the guild contributed to the guild's inclusive atmosphere and fostered a sense of empowerment among individuals who belonged to the guild. First, I will detail the data and methods used for this study; then, I broadly describe the role of surveillance in World of Warcraft in general, followed by a description of the guild's particular rules and methods for enforcing the rules. Finally, I detail the responses and reactions from members of the community to this surveillance.

\section{Data and Method}

The data for this work come from a five-year (2007-2012) participant-observation ethnographic study of a World of Warcraft guild called <Ragnarok>. <Ragnarok> was a self-labeled "safe space" gaming community for minority players including women and LGBT individuals. ${ }^{1}$ The project involved regular interaction with the community and the environment using the method of digital ethnography (e.g. Boellstorff 2008; Nardi 2010) and was a structured project for a dissertation. I was embedded in the

\footnotetext{
1 This guild name is a pseudonym. For those readers interested in World of Warcraft guilds with a similar safe space mission, see Appendix A for an abbreviated listing.
} 
community as a regular player and guild member, participating in guild events at all levels of play as a competent player in order to gain a deep level of understanding of the game and its players. As Bonnie Nardi said in her World of Warcraft ethnography, "It would be impossible to penetrate the game without being engaged as a player" (2010: 28). During part of my time in $<$ Ragnarok $>$, I also had the opportunity to be part of the guild's leadership structure by serving as an officer in charge of coordination of guild activities, which allowed me to understand how leaders of a guild manage their duties and the needs of guild members. This gave me a unique insight into the administration of these rules and the punishments handed out when the rules were broken.

Text chat data were collected using the built-in /chatlog function in World of Warcraft, which saved all text chat that occurred on my screen in a text file on my computer. Names have been replaced with pseudonyms and any identifying information was removed from the text chat data. One-on-one interviews were conducted with fifteen regular, long-time members of the guild. These interviews were conducted over Ventrilo, voice-over-IP software that was a preferred voice communication platform for the guild; the interviews were transcribed and any identifying information included in the interview was removed. As a final source of data I use my own ethnographic observations recorded in a research notebook; these observations record my experiences both as a player and a researcher in my time observing the guild.

It has been argued that the participant-observation ethnographic method introduces researcher bias since the researcher has an active stake in the phenomena being discussed. The researcher can alleviate the bias such as being accountable for their own actions and, where possible, triangulating their observations with other sources of data (see Collins and Gallinat 2010 for an excellent discussion of ethnographic bias). In this work, I use the words and actions of other players to supplement my observations, quoting them directly where possible. When I found myself in a leadership role actively enforcing the system that I document in this study, I did my best to model my own interactions off of those I had observed from others, however uncomfortable it made me as an individual. I also attempted to talk through any disciplinary actions with other leaders to ensure that I was acting within the bounds of the guild in a realtime version of the deliberative discussion methods documented by Laura Black and colleagues in their study of Wikipedia governance (2011). This gave a unique insight into the workings of this system that I would not have been able to gain had I not had the leadership role.

With these data and methods established, I now turn to a discussion of the surveillance culture and system in place in World of Warcraft during my ethnography.

\section{Surveillance in World of Warcraft}

Players of the massively multiplayer online roleplaying game (MMORPG) World of Warcraft (WoW) are accustomed to multiple modes of surveillance of their behavior. First is the one-way "paternalistic" style of surveillance (Regan and Steeves 2010) in which players are being watched by those in control. In World of Warcraft, powerful figures known as the Game Masters (GMs) represent the company that owns the game, Blizzard Entertainment. The GMs are always around as the unknown others watching player behavior both in-game and on Blizzard websites such as the forums; they respond to player requests for help as well as complaints about other players, but they also are ready to intervene should a player engage in prohibited activities (which include using illegal game hacks, stealing from other players, and using threatening or harmful language towards others). In addition to the GMs monitoring player behavior, the players are aware that Blizzard Entertainment keeps a record of chat in the game to investigate infringements or bad behavior after the fact. Players can submit complaints about bad behavior, and while their complaints are acknowledged by the GMs, they are never publicly acted upon. Offending players may be banned from the game for a length of time or be otherwise disciplined, but the player who reported the offense is never informed about the outcome of their complaint. While Blizzard reports that they take their harassment policies very seriously, there is a lack of information available about how the system is 
working, which leads some players and guilds to develop their own systems of preventing harassment which they can enforce and control themselves. This development of other systems of control and regulation is not unique to World of Warcraft guilds; in fact, as Wall and Williams (2007) suggest, alternative styles of governance are an integral part of the histories of online cultures, whether they lead to the community managing itself or to deviance from broad community norms.

Therefore, in co-existence with Blizzard's institutional, unilateral style of surveillance are several forms of participatory surveillance. The most oft-observed example of participatory surveillance in World of Warcraft is the phenomenon of players observing each other's performance in game situations for the purpose of increasing playing ability, group efficiency, and game progression. T.L. Taylor's (2008) work on user interface surveillance modifications (mods) provides an excellent overview of this phenomenon and the players' view of this type of surveillance. Taylor discusses two types of surveillance mods: player performance mods and group observation mods.

Player performance mods such as damage meters measure a player's overall damage to enemies and rank players in the group according to the amount of damage that they do. Players will often share the results of these meters in group chat channels either to show off their own playing prowess or to report on the abilities of the group. Player performance mods can be playful objects by "letting people tease each other and engage in friendly competition by sharing the rankings," but because these mods have limitations in what they can observe, "some can feel that their contributions are not meaningfully accounted for or, just as important, represented" (Taylor 2008: 190). In this way, Taylor argues that these mods can be used as a tool for stratification according to playing ability measured in certain, non-comprehensive ways. Yet the damage meters are assumed to be part of the experience in group activities in World of Warcraft, and experienced players know that their performance is always being watched by at least some members of the group. In this way, players are accustomed to being watched by partially known others who are observing their playing ability as reported by damage meters.

The other type of surveillance mod is the raid assistant and observation mods, which monitor player behaviors as well as what gear they are wearing and what they are carrying in their bags. These are typically used during raids to ensure the highest performance level of one's group members in situations that require high degrees of skill, awareness, and reaction to accomplish the group's goals. The leaders of the group can use these mods to reprimand misbehaviors such as when a group member wanders too close to an enemy and engages its attention before the rest of the group is ready, or when a player does not have all of the potions or food required to boost his or her statistics to the highest level. Generally, players in these high level events know that they are being observed in such a way, and yet there is still a feeling of discomfort for some regarding these mods. Taylor describes her first encounter with this type of mod during her study of the game: "...I immediately felt a knot in my stomach. It was almost as if I had done something wrong already. It was not just that suddenly my experience of the encounter became one in which there was no room for error, but that I was somehow being scrutinized (or at least potentially so) in a way that I had not anticipated" (2008: 192). The possibility some sort of punishment by one's superiors in the raid group was cited as a source of player discomfort with this type of surveillance mod.

While these mods are not intrinsic to the game's interface, Taylor notes that much of the game's most advanced events could not be completed or even attempted without them. I, too, observed this during my ethnography - it was a requirement before joining my first raid that I had two mods installed, one of which was a damage meter, and the other was what was called a "threat meter" which monitored my behavior and let the raid leader know when an enemy turned its attention to me. These mods were such a part of gaming culture that it was unthinkable to do a serious raid without them, and when I became the leader of a guild and raids for a time, I required that my team members have these mods installed. 
Both Taylor's observations and my own confirm that these types of surveillance are seen as quite normal in the game environment even if they may cause some players discomfort. To the average player, the very act of participating in a high level end-game event means consenting to being watched and observed by both the leaders of the event as well as the other participants - to not consent is to not be allowed to participate. This kind of participatory surveillance is a part of the game that is expected by participants in raids - players monitor themselves as well as others to make sure not only that they are doing their jobs, but that their performance is measuring up with others. However, in my ethnography, I observed a form of participatory surveillance that served a different purpose: community building and monitoring.

\section{Participatory Surveillance and Community in <Ragnarok>}

Guilds are game-sanctioned social organizations which are created and run by players and can serve different purposes: some guilds are pre-existing groups of friends, others are devoted to gathering the best players to master all of the game's content, while others are organized around a topic like roleplaying or player-versus-player combat (Williams et al. 2006). Members of guilds gain special benefits like access to a communal bank, abilities like mass resurrection for dead players, and a social group to engage with as they navigate through the game.

Guilds, as a social structure, have been the subject of other studies. Nardi and Harris (2006) studied collaboration in guilds as well as in spontaneous interactions in World of Warcraft. They describe how the variety of types of collaboration available in-game made the game more enjoyable for participants; however, they also described the beneficial role of tight-knit groups in increasing player enjoyment. Groups (or guilds) in which the players felt connected to each other had members who reported enjoying the game more, and there are a number of factors that contribute to this tight-knit feeling (e.g. working together on a task, having a common interest, sharing connections outside of the game world). However, it is difficult to achieve a guild that is set up in this way, as described by Chen, Sun, and Hsieh (2008) in their work on the life cycle of guilds. They explore the ways that the dynamics of a guild are an intersection of player motivation and game design - for example, the game designers' focus on endgame events rather than the character leveling experience leads to the proliferation of guilds that consist of large groups of maximum-level characters piloted by players with extensive game experience. There is little room for the new players, or "noobs", in a system like this; furthermore, this type of guild tends to favor performance in endgame events over personal connections that were described by Nardi and Harris. The key is to balance the goals of the guild with the connections between players, which is a difficult task to manage. This is exacerbated by the fragility of guilds reported by Ducheneaut, Yee, Nickell, and Moore in their 2007 work on the success and failure of guilds in World of Warcraft. They suggest that one of the traits that leads to guild failure is the number of people growing too large; in fact, they suggest the optimum number of people in a guild to be 35 . When a guild grows beyond this size, resources (including social interaction) can become too spread out and players can become less invested in the guild. Ducheneaut and his colleagues suggested that a way to circumvent this phenomenon is to partition the members into subgroups who focus on a particular task, which means that "the guild itself serves as a broader social environment" (2007: 848).

$<$ Ragnarok $>$ was a peculiar social object in World of Warcraft in that it was created by a female player and designed to be a "safe space" for people marginalized by the wider $W o W$ population, including women and LGBT players. ${ }^{2}$ Unlike other guilds of a similar nature that I observed throughout the course of my ethnography, this guild was also committed for most of its existence to a high performance level in end-game raids. Usually, guilds that focused heavily on social rules catered to a more casual player; in the case of $<$ Ragnarok $>$, the guild served as a safe space for players who played World of Warcraft at more

\footnotetext{
2 For more details on how discourse and rhetoric contribute to the marginalization of these individuals in World of Warcraft, see Nardi's (2010) discussion of "the boys' tree house" and masculinist rhetoric.
} 
advanced levels (see Collister 2013 for an in-depth description of how the higher level of play impacted the behavior and operations of the guild). The safe space mentality fostered greater connections between the guild's members as they were united in ideology, as well as concentrating guild activities on the endgame events that are one of the major focuses of World of Warcraft's design. Some members were in the guild to focus on the raiding events while others were there to enforce the guild as a safe space. These groups were connected by participating in the same events and being subjected to the same rules of the guild as a safe space.

To maintain this safe space, the guild had a number of rules for behavior written into its charter by the creator of the guild, Averik. This charter was posted on the guild's website, which was linked in the "Guild Information" tab in the game itself. Beyond Blizzard's game-sanctioned punishments for inappropriate language use in-game, the guild imposed its own penalties in the charter that applied to all members. The rule that I will focus on in this work was the zero-tolerance "hate speech" rule. The rule as written in the $<$ Ragnarok $>$ charter was:

We are a hate-free zone. This means that there is no hate speech in the guild. We are friendly to all races, genders, sexualities, nationalities, etc. If you use any hate speech (yes, this includes using "gay" as a synonym for "stupid"), you will be swiftly and harshly reprimanded. Using hate speech shows disrespect, and you never know who you are disrespecting.

While this rule was notably vague, in practice players knew that using any language that could be deemed a "slur" was unacceptable. This rule was modeled on one in the game's official harassment policy as listed on Blizzard's website (2013) and enforced by surveillance by the GMs of Blizzard Entertainment; however, in contrast to the opaque way that GMs handle player complaints without informing the affected parties of the results of their complaint, in $<$ Ragnarok $>$ violation of the rule had tangible outcomes that the players could observe. Furthermore, the scope of the policy was expanded to include other modes of interaction beyond those that could be policed by the GMs. These observable signs of the safe space serve as a public show of support, which is a method of creating safe space boundaries often recommended to LGBT ally programs (Poynter and Tubbs 2008).

The most often policed mode for this rule was the guild's voice chat platform, Ventrilo. As suggested by the charter's wording, the most problematic culprit was the casual use of slurs involving sexuality, such as "gay" as a synonym of bad. This particular use of "gay" has been studied in non-gaming contexts, and its use has found to be negatively associated with the well-being of non-heterosexual hearers (e.g. Lalor and Rendle-Short 2007; Woodford et al. 2012). Problematically, most users of this form of "gay" do not realize the implications of this meaning, and think that it's "no big deal" to use sexuality-based slurs in this way (Chonody, Rutledge, and Smith 2012). Part of the guild's evolving mission was not only to avoid offensive players, but to educate its members about the way their use of language can negatively affect others, specifically focusing on the problematic use of "gay" but extending to similar types of language.

Although online governance is typically conducted by a select few members of the community (Butler et al. 2007), the hate speech rule was actively policed by the officers of the guild as well as casual members who supported the guild's safe space mission. Repercussions for violating the rules varied depending on the offense. A casual use of an offensive term by someone who was ignorant of its meaning or effects resulted in a discussion with the player with the aim to educate them about their language use. A minor first offense in the game's text chat resulted in a warning, preferably done in a mode that minimized the embarrassment of the offending party such as a one-to-one text chat message in the game. However, most times a Ventrilo-based offense would be handled verbally in the Ventrilo channel immediately after its occurrence, resulting in a visible public reprimand. That is, if a player in the guild used prohibited language on Ventrilo, one or more officers - or even long-time guild members-would respond 
immediately in the same Ventrilo channel reprimanding the speaker. This was done to demonstrate publicly that the guild's membership would not tolerate such speech, and to serve as a warning for others. Sometimes, this caused embarrassment or anger on the part of the offending party; during my time in the guild's leadership, a guild member quit the guild immediately in the middle of an event because he was so incensed that I reprimanded him for calling one of the game's primary antagonists, the Lich King, a "fag" (a derogatory term for a gay male, short for "faggot") in Ventrilo.

More offensive infractions, especially targeted degrading remarks about members of the guild based solely on their gender, sexuality, or ethnicity were not tolerated and often resulted in the offender being removed from the guild. A chat transcript from November 2007 illustrates these consequences - the guild leader, Averik, interacted with a guild member, Teryn, who had joined the guild recently and obviously had not read the rules.

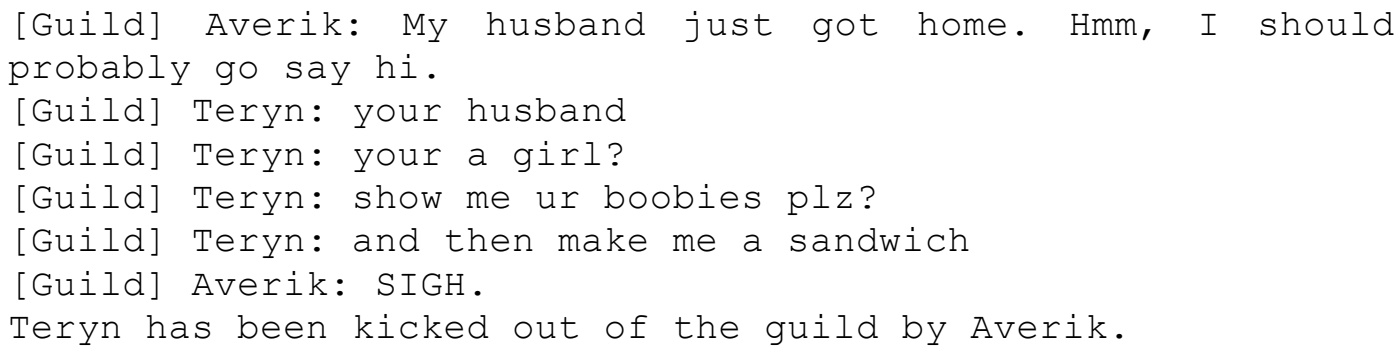

This interaction is an example that might be considered commonplace in the broad World of Warcraft community and which might not receive punishment from the GMs; however, in $<$ Ragnarok $>$, this was unacceptable. With new or relatively unknown players like Teryn, such offenses often resulted in immediate the removal of the player from the guild.

The public consequences of rule violations came about as a result of community surveillance and are a form of soft power and social regulation. Soft power, defined by Steger (2005: 32), is "the use of cultural and ideological appeals to effect their desired outcomes without commanding allegiance." Soft power is contrasted with hard power, which is the use of force, either economic or physical, to elicit desired outcomes (Fairclough 2010: 463). The form of soft power used by the guild draws on ideological power (or a way of normalizing community behavior, see Kiesling 2007: 370) and takes the form of public reprimand, a less severe type of shaming. Shaming is defined as "the process by which citizens publicly and self-consciously draw attention to the bad dispositions or actions of an offender, as a way of punishing him for having those dispositions or engaging in those actions" (Kahan and Posner 1999: 368). Shaming is a form of deterrence, inhibiting behaviors through social disapproval (Grasmick and Brusik 1990). According to Toni Massaro's (1997) work on shaming in legal contexts, shaming can be a particularly effective tool in close-knit communities that have shared expectations of behavior. The public reprimands in $<$ Ragnarok $>$ align with these descriptions of shaming $-<$ Ragnarok $>$ is a close-knit community with a shared written code for behavior, and by expressing public disapproval of the use of offensive language, the members attempted to inhibit its use by others. However, shaming is often characterized as a repeated behavior aimed to elicit humiliation in the target (see Skoric et al. 2010); the public reprimands in $<$ Ragnarok $>$ were one-time events that aligned with a stated code of conduct, which is why I characterize them as a less severe form of shaming. Skoric et al. suggest that shaming can be viewed as soft power, which operates differently from the laws and the penalties of hard power (2010: 190). <Ragnarok>'s members, then, were exercising their own versions of soft power (or, occasionally, hard power in the case of Averik and Teryn above) over the other members of their organization, while the hard power rested with the distant GMs of Blizzard who could impose penalties such as banning an offending player from the game. The power wielded by the guild's members was contingent on vigilant participatory surveillance. 
Participatory surveillance was employed in $<$ Ragnarok $>$ to enforce the community's boundary with the rest of the $W o W$ population with respect to such language. As a consequence to having these rules in place and having them actively and aggressively enforced by the guild's leadership and members of the guild, $<$ Ragnarok $>$ became a safe space for players to express themselves without fearing a personal attack based on their identity. Since a safe space is not a physical place but rather "an imaginary construction on "ritual forces of control" (Audrey Thomson, quoted in Stengel and Weems 2010: 505), the need arose for the members of the guild to visibly control and enforce their boundaries. Therefore, public reprimands were deemed appropriate for these cases of obvious violation of the rules because of the guild's identity-the guild is a safe space and the members needed to demonstrate that it was against their rules to use this type of language, and by publicly disciplining the offenders they could deter future violations. These acts worked to show that there were consequences for violating the rules of the guild, and were in direct contrast to the lack of visible enforcement of harassment rules by the Blizzard GMs.

\section{Empowerment Through Surveillance}

Because of the active enforcement of the "hate speech" rules, players monitored both their own language as well as the language of their fellow guild members. Discipline for breaking the rules resulted in players taking the enforcement of the safe spaces into their own hands, which led to a feeling of empowerment on many different levels. During interviews with members of the guild, I specifically asked about their reaction to these rules to understand how their participation in the surveillance of language and the maintenance of their safe space contributed to their feelings of empowerment and safety in the guild. Players responded positively to the rules, saying that "it's a nice change of pace from the rest of the guilds I've been in" (Mindy), "it made me feel safe speaking my mind" (Theon), and "for once, I don't have to worry about being offended by every word that comes out of someone's mouth" (Eversoul). One player, Rawka, responded more negatively to the public aspect of discipline than the rules themselves, saying that he thought "some of the reactions to using the terms were a bit over the top, but some people have to be yelled at before they get anything." Rawka as a player often responded in a mild, private way to players breaking the language rules in the guild, explaining patiently in a private conversation why they were wrong; however, in his own way, he still participated in the surveillance and took the methods for correcting behavior into his own hands.

Some members of the guild, particularly the youngest members, had difficulty conforming to the hate speech rule at first, mostly because of the proliferation of the term "gay" in American culture. They had to first change their own usage, which was very difficult for some. Kovax, who joined the guild at the age of 13, described the way he changed his language:

...with <Ragnarok>'s rule, when I first joined, with the whole not saying "gay" and "faggot" and all that, it took me a while to get used to but now it's a rule that's been burned into my mind. I don't say, you know, "That's gay" anymore. I say that like "That's uncool" or something.

Through constant reminders from the community and seeing others be punished for their usage, Kovax had the rule "burned into" his mind and learned to observe and change his own habits. Surveillance, for Kovax, resulted in personal empowerment to change his own behaviors. Another long-time member of the guild, Chromus, joined the guild at age 14 and, years later, described his personal journey in eliminating the use of "gay" from his own speech:

When I first started playing the game [...] I was the normal 14 year old boy, you know, where everyone would say comments like "oh that was so gay," "you're so gay," and I didn't think anything of it. It was just another word like "you're so stupid" but $[\ldots]$ that's very wrong. And the fact that I didn't see that it was wrong was very disturbing because, 
you know, just because someone has a different preference than you doesn't mean-like why should you use their label as a derogatory term? And it was very eye-opening and since then I have never used that term as a derogatory term and I will actually correct people when they do use it.

Chromus's report of empowerment has gone beyond the personal-now he reports participating in surveillance of others, correcting them when they use language inappropriately. Chromus also reported in his interview that he has taken this behavior beyond the game, and that now he feels more comfortable "working with people from all kinds of backgrounds" because of his experiences in $<$ Ragnarok $>$.

Group empowerment was felt in a different way for other members of the guild-Mindy, who joined the guild with her husband Walter, described that she felt "[she] genuinely was accepted by the group as a player and friend, not just as an add-on, Walter's wife." Another female player, Eversoul, remarked, "Other guilds, I get the side-eye sometimes like, 'oh you're female.' Never here. It's nice not having to worry." Theon, a gay man who was an officer of the guild, responded that he "didn't feel the need to hide or sit back and take it [harassment for being gay], that there were people who would stand up" for him. The interpersonal and group connection helped empower individuals to feel genuinely wanted and appreciated and part of a group.

Laira, a bisexual woman who served as the guild leader during part of my study, responded that she "felt like we were contributing in a small way to a larger goal of making spaces safe for women and LGBT folks." In her interview, she referenced the growing acceptance of women in gaming communities as well as the "movement for equality of LGBT people in the US." Laira's comments specifically target a citizenship level of empowerment - feeling connected to a larger movement and being part of enacting social change. Laira in particular took her empowerment to the next level by organizing a breast cancer awareness and fundraising event in World of Warcraft that was connected to the guild's ideologies about safe spaces for women.

These empowerment experiences may not have been possible were it not for the active participatory surveillance in place in the guild. Putting rules into place requires enforcement, and in this case the enforcement was enabled by constant multifaceted surveillance. Even though Blizzard Entertainment has similar rules in place for the whole of World of Warcraft and there are Game Masters recording chat and able to punish players for infringement, the invisible and unilateral surveillance has not resulted in social change or player empowerment. The GM surveillance occurs passively at a distance, characterized by "chains of intermediaries which link the watched to some distant watcher" (Ball et al. 2009: 354); in contrast, the surveillance in $<$ Ragnarok $>$ was done by peers who are known to the players, and who, in many cases, wield power actively to demonstrate the importance of the rules. Players changed from passive subjects obeying the directives of unknown others to active agents who embraced and enforced the rules to promote their own community. The activeness of the surveillance in the enforcement of community boundaries is the reason that such empowerment was possible on both an individual and a group level.

\section{Conclusion}

In this work, I have shown how participatory surveillance of behavior contributed to individual and group empowerment in a World of Warcraft guild. World of Warcraft has an established surveillance culture with both paternalistic, top-down surveillance in the form of Blizzard Entertainment's GMs as well as the player-created lateral surveillance mods described by Taylor (2008) which monitor the playing ability and actions of other players. The case study of $<$ Ragnarok $>$ presented a different kind of surveillance that interacts with the extant surveillance model, specifically using participatory surveillance of guild members' language in conjunction with discipline in the form of public discipline. The public, visible, and 
active nature of surveillance and enforcement of guild regulations allowed - and, in fact, encouraged - its members to participate in the surveillance. This participation led to individual development for players in the guild who were part of marginalized groups, but also for young people who were being exposed to identities and communities that they had not encountered previously.

The participatory nature of the surveillance was a defining aspect of the "safe space" that was this World of Warcraft guild. Lessons can be learned from this case study about the different results of unilateral and participatory surveillance, as well as the benefits of active and visible surveillance and punishment. Paternalistic, top-down surveillance was often described as unsatisfactory for players who did not see the outcomes of their complaints. Participatory surveillance of behavior was more satisfactory for players because it increased feelings of agency and safety in the community; furthermore, the enforcement of rules with public reprimands helped members of the group feel like the rules were important and had tangible results. While participatory surveillance like the example of $<$ Ragnarok $>$ often arises organically within the community, examples such as the Tribunal in League of Legends illustrate how this additional level of participatory surveillance may be incorporated into the game's interface and mechanics and controlled by the parent company (Riot Games Inc. 2011). To have distant, unknown watchers enforcing global rules is a common and necessary construct in these communities; however, an additional layer of participatory surveillance is an effective way to foster individual and community growth and increased safety for players who are often marginalized in gaming environments. When a player has agency and feels safe in their environment, there are more opportunities for a fun and engaging gaming experience.

\section{Appendix A: List of Safe-Space World of Warcraft guilds}

This listing is necessarily incomplete as the guild landscape in World of Warcraft is constantly changing. However, several of these guilds have been in existence for many years, and this list should serve as a starting point for any readers interested in safe space guilds.

$<$ Stonewall Champions $>-$ Proudmoore-US (Alliance) - http://stonewallchampions.org

$<$ Taint $>$ - Proudmoore-US (Horde) - http://taint.dkpsystem.com

$<$ Noesis $>-$ Detheroc (Alliance) - http://noesis.mmoguildsites.net/

$<$ Ursus $>$ - Aggramar-US (Horde) - http://ursus.guildomatic.com

$<$ SeeD $>-$ Scarlet Crusade-US (Alliance) - http://seedguild.info

$<$ Full Spectrum $>-$ Alleria-US (Alliance) $-\underline{\text { http://www.fullspectrumguild.com }}$

$<$ The Violet Star $>-$ Defias Brotherhood-EU (Horde) - http://violetstar-db.weebly.com

$<$ Silverflare Syndicate $>$ - Nordrassil-EU (Alliance) - http://silverflare.shivtr.com/

$<$ Equinox $>-$ Outland-EU (Horde) - http://equinoxoutland.com

\section{References}

Albrechtslund, Anders. 2008. Online Social Networking as Participatory Surveillance. First Monday 13(3). Accessed September 1, 2013. doi:10.5210/fm.v13i3.2142

Albrechtslund, Anders, and Lynsey Dubbeld. 2005. The Plays and Arts of Surveillance: Studying Surveillance as Entertainment. Surveillance \& Society 3(2/3): 216-221. Accessed August 1, 2013. http://ibrary.queensu.ca/ojs/index.php/surveillanceand-society/article/view/3502

Andrejevic, Mark. 2005. The Work of Watching One Another: Lateral Surveillance, Risk, and Governance. Surveillance \& Society 2(4): 479-497. Accessed August 1, 2013. http://ibrary.queensu.ca/ojs/index.php/surveillance-andsociety/article/view/3359

Ball, Kirstie S. 2009. Exposure: Exploring the Subject of Surveillance. Information, Communication, and Society 12(5): $639-657$. Accessed August 15, 2013. doi:10.1080/13691180802270386

Ball, Kirstie S., David J. Phillips, Nicola Green, and Hille Koskela. 2009. Editorial: Surveillance Studies Needs Gender and Sexuality. Surveillance \& Society 6(4): 352-355. Accessed August 15, 2013. http://library.queensu.ca/ojs/index.php/surveillance-and-society/article/view/3266/3229

Black, Laura W., Howard T. Welser, Dan Cosley, and Jocelyn M. DeGroot. 2011. Self-Governance Through Group Discussion in Wikipedia Measuring Deliberation in Online Groups. Small Group Research 42(5): 595-634. Accessed August 1, 2013. doi:10.1177/1046496411406137 
Butler, Brian, Lee Sproull, Sara Kiesler, and Robert Kraut. 2007. Community Effort in Online Groups: Who Does the Work and Why? In Leadership at a Distance: Research in Technologically-Supported Work, edited by S. Weisband, 171-194. Mahwah, NJ: Lawrence Erlbaum.

Blizzard Entertainment. 2013. Harassment Policy. Last modified September 4. https://us.battle.net/support/en/article/harassmentpolicy

Boellstorff, Tom. 2008. Coming of Age in Second Life: An Anthropologist Explores the Virtually Human. Princeton: Princeton University Press.

Chen, Chien-Hsun, Chuen-Tsai Sun, and Jilung Hsieh. 2008. Player Guild Dynamics and Evolution in Massively Multiplayer Online Games. CyberPsychology \& Behavior 11: 293-301. Accessed August 1, 2013. doi:10.1089/cpb.2007.0066

Chonody, Jill M., Scott E. Rutledge, and Scott Smith. 2012. 'That's so gay': Language Use and Antigay Bias among Heterosexual College Students. Journal of Gay \& Lesbian Social Services 24: 241-259. Accessed August 1, 2013. doi:10.1080/10538720.2012.697036

Collins, Peter and Anselma Gallinat. 2010. The Ethnographic Self as Resource: an Introduction. In The Ethnographic Self as Resource: Writing Memory and Experience Into Ethnography, edited by Peter Collins and Anselma Gallinat, 1-24. New York: Berghahn Books.

Collister, Lauren B. 2013. Multimodality as a Sociolinguistic Resource. PhD diss, University of Pittsburgh. http://dscholarship.pitt.edu/18514/

Ducheneaut, Nicolas, Nicholas Yee, Eric Nickell, and Robert J. Moore. 2007. The Life and Death of Online Gaming Communities: A Look at Guilds in World of Warcraft. In Proceedings of ACM CHI 2007 Conference on Human Factors in Computing Systems 2007, 839-848. New York: ACM.

Fairclough, Norman. 2010. Critical Discourse Analysis: The Critical Study of Language. New York: Routledge.

Grasmick, Harold G. and Robert J. Bursik, Jr. 1990. Conscience, Significant Others, and Rational Choice: Extending the Deterrence Model. Law \& Society Review 24(3): 837-862. Accessed August 15, 2013. doi:10.2307/3053861

Kahan, Dan M. and Eric A. Posner. 1999.Shaming White Collar Criminals: A Proposal for Reform of the Federal Sentencing Guidelines. Journal of Law \& Economics 41(1): 365-391. Accessed August 15, 2013. doi:10.1086/467429

Kiesling, Scott F. 2007. Power and the Language of Men. In A Cultural Approach to Interpersonal Communication: Essential Readings, edited by Leila Monoghan and Jane E. Goodman, 334-350. Malden, MA: Wiley-Blackwell.

Lalor, Therese and Johanna Rendle-Short. 2007. 'That's So Gay': A Contemporary Use of Gay in Australian English. Australian Journal of Linguistics 27(2): 147-173. Accessed January 15, 2013. doi:10.1080/07268600701522764

Martin, Jennifer. 2012. Second Life Surveillance: Power to the People or Virtual Surveillance Society? Surveillance \& Society 9(4): 408-423. Accessed August 1, 2013. http://library.queensu.ca/ojs/index.php/surveillance-andsociety/article/view/second_life

Massaro, Toni M. 1997. The Meanings of Shame: Implications for Legal Reform. Psychology, Public Policy, and Law 3: 645704. Accessed February 1, 2013. doi:10.1037/1076-8971.3.4.645

Nardi, Bonnie. 2010. My Life as a Night Elf Priest: An Anthropological Account of World of Warcraft. Ann Arbor: University of Michigan Press.

Nardi, Bonnie, and Justin Harris. 2006. Strangers and Friends: Collaborative Play in World of Warcraft. In Proceedings of the 2006 20th Anniversary Conference on Computer Supported Cooperative Work, 149-158. New York: ACM.

Poynter, Kerry J. and Nancy Jean Tubbs. 2008. Safe Zones: Creating LGBT Safe Space Ally Programs. Journal of LGBT Youth 5(1): 121-132. doi:10.1300/J524v05n01 10

Regan, Priscilla M. and Valerie Steeves. 2010. Kids R Us: Online Social Networking and the Potential for Empowerment. Surveillance \& Society 8(2): 151-165. Accessed August 15, 2013. http://library.queensu.ca/ojs/index.php/surveillanceand-society/article/view/3483

Riot Games Inc. 2011. Policy and Procedure for 'The Tribunal'. Last modified April 12. http://beta.na.leagueoflegends.com/legal/tribunal/

Skoric, Marco M., Jia Ping Esther Chua, Meiyan Andeline Liew, Keng Hui Wong, and Pei Jue Yeo. 2010. Online Shaming in the Asian Context: Community Empowerment or Civic Vigilantism? Surveillance \& Society 8(2): 181-199. Accessed August 15, 2013. http://library.queensu.ca/ojs/index.php/surveillance-and-society/article/view/3485

Steger, Manfred B. 2005. From Market Globalism to Imperial Globalism: Ideology and American Power After 9/11. Globalizations 2(1): 31-46. Accessed August 15, 2013. doi:10.1080/14747730500085049

Stengel, Barbara S. and Lisa Weems. 2010. Questioning Safe Space: An Introduction. Studies in Philosophy and Education 29(6): 505-507. Accessed May 7, 2014. doi:10.1007/s11217-010-9205-8

Taylor, T. L. 2008. Does World of Warcraft Change Everything? How a PvP Server, Multinational Playerbase, and Surveillance Mod Scene Caused Me Pause. In Digital Culture, Play, and Identity: A World of Warcraft Reader, edited by Hilda G. Corneliussen and Jill W. Rettberg. Cambridge, MA: The MIT Press.

Wall, David S., and Matthew Williams. 2007. Policing Diversity in the Digital Age: Maintaining Order in Virtual Communities. Criminology and Criminal Justice 7(4): 391-415. Accessed August 1, 2013. doi: $10.1177 / 1748895807082064$

Williams, Dmitri, Nicholas Ducheneaut, Li Xiong, Yuanyuan Zhang, Nick Yee, and Eric Nickell. 2006. From Tree House to Barracks: The Social Life of Guilds in World of Warcraft. Games and Culture 1(4): 338-361. Accessed March 1, 2013. doi: $10.1177 / 1555412006292616$ 
Woodford, Michael R., Michael L. Howell, Perry Silverschanz, and Lotus Yu. 2012. 'That's So Gay!': Examining the Covariates of Hearing this Expression Among Gay, Lesbian, and Bisexual College Students. Journal of American College Health 60(6): 429-434. Accessed February 1, 2013. doi:10.1080/07448481.2012.673519 